\title{
Profesores reflexivos: reinventar la práctica desde la innovación
}

\author{
Altair Alberto Fávero \\ Universidade de Passo Fundo \\ Marisa Fátima Roman \\ Aristeo Santos López \\ Universidad Autónoma del Estado de México
}

\section{Resumen}

La universidad debe encontrar un equilibrio entre la formación técnicoprofesional y la formación humanista-cultural. En relación con el concepto de formación académica, significa una revisión profunda de la práctica académica y personal en la formación de los profesores. El profesor debe elegir los caminos que lo conduzcan hacia la posibilidad de ser emancipador en cuanto a la construcción de su identidad personal y laboral; romper con los paradigmas de la regulación y atrapar el concepto de innovación en su cotidianeidad.

Palabras clave: Profesor reflexivo. Práctica emancipadora. Innovación. 


\section{Reflective teachers: reinventing the practice from innovation Abstract}

The university must find a balance between technical professional education and humanist cultural education. In relation to the concept of academic education, this means an in depth review of academic and personal practice in teacher training. The teacher must choose the roads that lead him or her towards the possibility of being an emancipator in what refers to the construction of one's personal and work identity; break away from the paradigms of regulation and cling to the concept of innovation during everyday life.

Keywords: Thoughtful teacher. Emancipated practice. Innovation.

\section{Professores reflexivos: reinventar a práctica a partir da inovação}

A universidade deve encontrar um equilíbrio entre a formação técnica-profissional e a formação humanista-cultural. Em relação ao conceito de formação acadêmica, significa uma profunda revisão da prática acadêmica e pessoal na formação dos professores. 0 professor deve escolher os caminhos que o conduzam à possibilidade de ser emancipado na construção da sua identidade pessoal e profissional; romper com os paradigmas da regulação e apropriar-se do conceito de inovação no seu cotidiano.

Palavras-chave: Professor reflexivo. Prática emancipadora. Inovação. 


\section{Introducción}

En el contexto donde se hace hincapié en la necesidad de que el profesor se forje como docente reflexivo, es esencial repensar las funciones tradicionales de la universidad y descubrir cuáles son las nuevas prácticas que deberá realizar para conseguir una plataforma de superación ante todos los desafíos, al mismo tiempo que pueda contribuir en la dimensión humana. En este proceso es imprescindible la participación de los profesores, así como la innovación de sus vivencias y prácticas pedagógicas, porque la situación educacional actual requiere una formación permanente por parte de ellos, la cual deberá contemplar una diversidad de intereses: las necesidades del docente y de los alumnos; la flexibilidad frente a los constantes cambios; el vínculo del conocimiento con la práctica; las acciones para la construcción de pedagogías y didácticas emancipadoras, entre otros elementos.

Por tanto, para empezar a dibujar los caminos, se puede mencionar la necesidad de inclusión de proyectos de innovación; la formación de equipos de trabajo y de investigación; la elaboración y difusión de materiales curriculares y didácticos a través de grupos de discusión, de los seminarios permanentes y de los cursos específicos. Además, tenemos el desafío de la construcción de un profesor como un ser consciente de su papel y de la nueva temporalidad, pues a él le compete filtrar y criticar las informaciones oriundas de la ciencia y de la tecnología, en el sentido de colaborar en la formación de su propia ciudadanía y de la de sus estudiantes; investigar, con una visión futurista, nuevas formas de enseñanza y aprendizaje; reacomodarse y actualizarse permanentemente; rehacer y reconstruir constantemente su praxis y reconstituirse como sujeto y profesional. (Lampert, 1998)

Considerando que los profesores y sus prácticas pedagógicas contribuyen enormemente durante este proceso de búsqueda de soluciones para los dilemas vividos no solo por la universidad, sino por la sociedad, ellos se vuelven también tema de estudios. Y es justamente esta reflexión sobre los profesores y sus prácticas pedagógicas lo que sigue a continuación.

En un primer momento, se debaten ideas acerca de los ejes de regulación y emancipación, bajo los cuales la modernidad fue tejiendo sus procesos de racionalización. Contexto que fue amalgamado por mecanismos de control, orden, disciplina y dictámenes universales emitidos por ideologías eurocéntricas, lo que permeó lo cotidiano, las acciones, actitudes, producción y pensamiento del hombre. De esta manera, la mecanización, la reproducción y la regulación han predominado en la formación del ser humano.

Acerca de la posibilidad de trabajarse en la construcción de un terreno fértil para la formación del profesor reflexivo, en la segunda parte del texto, se presenta la innovación como vía para la emancipación. Se reflexiona sobre la innovación que va más allá de su uso técnico, instrumental, pero que nace con el 
pensamiento de resignificarse como persona que está en el mundo y, por ende, como profesional. Por ello, se pone a discusión algunas inquietudes en relación al desafío de reinventarse y de innovarse. La innovación vinculada a la subjetividad, a los procesos de subjetivación, que es la construcción de uno mismo como ser humano y social, que impacta en el desarrollo de la identidad. Finalmente, en el tercer momento, las reflexiones finales.

\section{Formación para regulación o emancipación}

Dentro de una perspectiva que intenta rescatar la innovación en educación superior fuera de las concepciones funcionalistas, el sujeto innovador es el profesor, que funciona como orientador, supervisor o dirigente máximo del sistema; lanza las ideas y trabaja para su aceptación e implementación. El respaldo político y organizacional de los líderes constituye una pieza clave para el cambio que ha de producir la estrategia innovadora. Esta perspectiva, bastante conocida y utilizada en cada gestión de un sistema educacional, tiene sus bases epistemológicas dentro del carácter regulador y normativo de la modernidad, la que tiene su proyecto socio-cultural asentado en los pilares centrales de la regulación y de la emancipación.

La innovación puede servir tanto para la perpetuación de la modernidad como para su negación. Para comprender el concepto de innovación presente en la modernidad es necesario hacer hincapié en el modelo de racionalidad que constituye lo que se entiende como la ciencia moderna lla revolución científica posterior al siglo XVI), la cual se extiende a todas las ciencias, incluidas las sociales. Para Santos (1995), la racionalidad hegemónica de este paradigma mantiene fronteras bien nítidas entre el conocimiento científico (racional, objetivo y neutrol y el conocimiento no científico (irracional, subjetivista y valorativo). En este sentido, el verdadero conocimiento se constituiría exclusivamente dentro de la racionalidad científica, lo que sería condición única para su implementación eficiente en el proceso productivo, sin considerar las consecuencias sociales.

Las características de la ciencia moderna, como la observación, sin compromiso, la certeza ordenada y la cuantificación de los fenómenos están vinculadas a un proceso de cambio limitado, fragmentado y hasta autoritario, porque no desarrollan una articulación que potencialice las nuevas relaciones entre el ser, el saber y la acción. En este sentido, la innovación implica una rearticulación del sistema que, en contrapartida, se apropia de las energías emancipadoras contenidas en la innovación y las transforma en una energía reguladora, lo que se traduce como irracionalidades y aporías del proyecto de la modernidad, aunque siga asumiendo los propósitos ideológicos de la modernización.

Dentro de las prácticas y discursos recientes y anteriores de liderazgo 
educativos del estado con respecto a la implantación de reformas en el sistema educacional, es posible observar ejemplos claros de esta perspectiva. En general, las propuestas y las acciones vienen coincidiendo con el pilar de regulación y el principio del estado y del mercado, pues involucran las ideas de individualismo y la conversión de la ciencia y del saber científico en fuerza productiva.

Estas finalidades muestran un estado orientador-regulador de la vida práctica del ciudadano, que se ha volteado expresamente dentro el campo educativo hacia lo racional cognitivo-instrumental, enseñando una política de estado que se autodenomina "revolucionaria"1 pero que guarda la lógica de la conservación y sirve a los intereses del capital. Además, todas las reformas propuestas son orientadas hacia las cuestiones curriculares y, poco o nada se ha visto en relación a propuestas que tienen la mirada hacia la formación integral, holística del profesor.

Si estos parámetros continúan siendo deseables para responder a las cuestiones actuales, entonces, debemos estar de acuerdo con las políticas oficiales que se conforman dentro de esta lógica. Si, al contrario, pensamos en que deben pasar por reformas, por reflexiones y cambios, ello implicará la búsqueda de una nueva comprensión.

Se puede decir que una práctica innovadora no se da únicamente cuando ha sido pensada desde el centro hacia la periferia, sino también al haber sido trabajada en el contexto institucional de las relaciones, que son relaciones de poder. Una práctica innovadora no lo es por introducción acrítica de lo nuevo en lo antiguo, pero sí por guardar dentro sí el germen de la ruptura. ${ }^{2}$

En este orden de ideas, podríamos preguntar qué ruptura es esta, que implica cambios en determinadas circunstancias que han obligado a transformaciones mayores, incluso en pequeñas partes del todo con la idea de globalidad: cambios en los planes de estudios, en las formas de ver y pensar las asignaturas, en las formas de organizar una asignatura viendo su relación con la otra y sus relaciones y amarres conceptuales intrínsecos (Lucarelli, 1992); en las relaciones de poder dentro del salón de clase donde los sujetos son protagonistas de sus propias circunstancias y aprendizajes; el cambio en las relaciones entre base y decisiones centrales en las instituciones educativas; en el carácter epistemológico de la enseñanza de las asignaturas que se conectan a la investigación y a la extensión en una simbiosis productiva que no destaca relevancias; en la configuración de la docencia, donde estudiantes, personas de la comunidad, profesores de otros

1. Algunos autores, como Buenaventura Santos (1995), emplean el término revolucionario para los procesos reformistas.

2. La ruptura de los obstáculos epistemológico-político-pedagógicos es la posibilidad de sobrevivencia de la cultura y la nacionalidad, porque esa ruptura permitiría inventar las soluciones que es incapaz de generar la mente rutinaria. Aún es necesario detectar los elementos de ruptura del discurso pedagógico moderno latinoamericano, las alternativas transformadoras en algún sentido, las fracturas de la trama que dejan ver los orígenes y, por lo tanto, predicen la posibilidad del futuro. (Puiggrós, 1990, 114-119) 
grados de enseñanza, investigadores, funcionarios técnico-administrativos y profesionales diversos son todos "docentes" de saberes diferentes.

Pensando en una educación emancipadora, vale la pena estar de acuerdo con Santos (1995) en que la desconstrucción de la ciencia, emprendida en esta perspectiva, se inserta en una totalidad orientada hacia la creatividad y la emancipación individual y social que, tal vez por eso, pueda estar sujeta a algunos principios de orientación tales como:

a. Para construir instituciones democráticas y democratizantes de la sociedad desde el punto de vista económico, político y cultural, es necesario atenuar el desnivel de los discursos, a fin de que ellos puedan hablar y orientar nuevas prácticas efectivas y dinámicas como producto de la interpenetración de los lenguajes de los sujetos;

b. La dicotomía contemplación/acción tiene dominado el pensamiento occidental y alcanza su ápice en la ciencia moderna. La superación de esta dicotomía presupone una aproximación del saber científico y de la acción social no limitada a los aspectos tecnológicos de la acción instrumental, así como la necesidad de la crítica al control público en su ampliación de la praxis hacia la técnica;

c. Buscar un nuevo equilibrio entre adaptación y creatividad. La construcción científica y tecnológica en las instituciones de enseñanza, está orientada para el proceso adaptativo de los sujetos. Debe ser reflexionada en el contexto de una praxis globalmente entendida y servida por una comprensión de la ciencia que auxilie al hombre a pensar sobre las consecuencias de estos procesos, para revitalizar la condición posible de la libertad humana.

Según Santos (1995), en este orden de ideas, la modernidad comporta dos formas principales de conocimiento: el conocimiento como regulación y el conocimiento como emancipación. El primero de estos consiste en la delimitación de una trayectoria entre un punto de ignorancia designado por el caos hasta un punto de conocimiento designado por el orden. El segundo, por su parte, consiste en el trazo de una trayectoria que va desde un punto de ignorancia llamado colonialismo hasta un punto de conocimiento llamado solidaridad.

A pesar de que estas dos formas de conocimiento están igualmente inscritas en la modernidad, la verdad es que en el último siglo el conocimiento como regulación ganó primacía sobre el conocimiento como emancipación. Con esto, el orden pasó a ser la forma hegemónica de conocimiento y, el caos, la forma hegemónica de la ignorancia. En la medida en que la ciencia moderna fue ganando terreno sobre formas alternativas del conocimiento -los saberes locales, la religión, la filosofía y las humanidades- $y$, sobre todo, en la medida en que se fue convirtiendo en fuerza productiva del capitalismo industrial, el equilibrio entre las dos formas 
de conocimiento se rompió y la ciencia moderna pasó a ser conocimiento como regulación por excelencia.

Al instaurar el proyecto pedagógico que propone la modernidad, según Santos (1996), se tendría otro conflicto epistemológico. Si bien los conflictos entre el modelo técnico y el modelo edificante de la aplicación de la ciencia y entre el conocimiento como regulación y el conocimiento como emancipación ocurren dentro de los límites de la modernidad eurocéntrica, nace otro conflicto, ahora epistemológico, que traspasa estos límites y se vuelve un conflicto cultural. Dice Santos (1996, p.26):

El mapa cultural que subyace a los sistemas educativos de la modernidad es, cartográficamente hablando, un mapa con una proyección de mercader, el gran cartógrafo de los países bajos cuyas técnicas de proyección cartográficas fueron adoptadas por toda la Europa a partir del siglo XVII. La característica central de la proyección del mercader es que coloca el continente europeo en el centro del mapa, privilegiando su dimensión en detrimento de los otros continentes. En términos simbólicos, el mapa educativo de la modernidad es un mapa de Mercader. La cultura eurocéntrica ocupa casi todo el tamaño del mapa y sólo marginalmente, y siempre en función del espacio central, son diseñadas las otras culturas indígenas, culturas negras y culturas de minorías étnicas u otras. Es este el mapa del imperialismo cultural del Occidente. En este mapa el conflicto entre culturas o no aparece del todo o aparece como conflicto solucionado por la superioridad de la cultura occidental con relación a las otras culturas. Por eso, en el sistema educativo hegemónico las otras culturas 0 están ausentes o están merecidamente vencidas, marginalizadas, suprimidas.

Tal como en los conflictos anteriores, en el campo pedagógico es necesario crear, a través de la imaginación, una conflictualidad que es negada por el modelo hegemónico. Del mismo modo, tiene que crear espacios pedagógicos para el multiculturalismo en cuanto modelo emergente de la interculturalidad. El modelo dominante del imperialismo cultural no reconoce otro tipo de relaciones entre culturas que no sean las de la jerarquía según criterios universales, aunque estos sean específicos de un solo universo cultural, la cultura occidental. A la luz de estos criterios, es la superioridad propia de las culturas dominantes la que justifica la existencia de culturas dominadas. Esta superioridad puede afirmarse de varias formas, incluso a través de formas que aparentemente niegan la idea de jerarquía como la hibridación y la cultura global. De esta forma, compete al campo pedagógico emancipador crear imágenes desestabilizadoras de este tipo de relación entre culturas, imágenes creadas a partir de las culturas dominadas y de la marginación, la opresión y el silenciamiento a que son sujetos los grupos sociales que son sus titulares.

En el contexto actual, estos grupos, así como continentes que silenciaban, empiezan a cobrar sus visibilidades y sus derechos de ejercicio de la ciudadanía, lo que por siglos les fue negado u omitido. Así, la pobreza en que son sometidos 
millones de habitantes de la tierra; el desempleo y la falta de formación para el mundo laboral; el aumento población del planeta; el deterioro del medio ambiente; la guerras; la falta de planeación de las ciudades; la inequidad de distribución económica; la corrupción de los gobiernos, son apenas algunos de los temas que comienzan a cobrar sus facturas. De igual manera, las mujeres en la búsqueda de sus reconocimientos y derechos; los niños y ancianos que se vuelven sectores vulnerables; los indígenas; las personas con discapacidad; las personas con otras preferencias sexuales que no sea heterosexual; los negros; las distintas religiones; etcétera.

Siendo así, dentro de la innovación educativa en la construcción de un proyecto pedagógico emancipador, se propusieron tres grandes conflictos epistemológicos: el conflicto entre la aplicación técnica y la aplicación edificante de la ciencia; el conflicto entre el conocimiento como regulación y el conocimiento como emancipación; y el conflicto entre el imperialismo cultural y lo multicultural.

Santos (1996) defiende que estos conflictos deben ocupar el centro de toda la experiencia pedagógica emancipadora. El conflicto sirve, ante todo, para vulnerar y desestabilizar los modelos epistemológicos dominantes y para mirar el pasado a través del sufrimiento humano que, por ellos y la iniciativa humana, fue causado sin disculpa alguna. Esta mirada producirá imágenes desestabilizadoras susceptibles de desarrollar en los estudiantes y en los profesores la capacidad de espanto e indignación y la voluntad de rebeldía y de inconformidad. El individuo autónomo y consciente de sus fines debe de ser recuperado; su emancipación solo será posible en el nivel individual al resolverse el conflicto entre la autonomía de la razón y las fuerzas obscuras e inconscientes que invaden esa misma razón. La innovación, en este sentido, tiene como ejes: la ciencia que posibilita la calidad de vida; el conocimiento como vía emancipadora en cuanto a su impacto en los procesos de saber, poder y de subjetivación. (Foucault, 1983; 1991; 1995; 2005)

Esta capacidad y esta voluntad serán fundamentales para mirar con empeño los modelos dominados o emergentes a través de los cuales es posible aprender un nuevo tipo de relación entre saberes, personas y grupos sociales: una relación más igualitaria y justa; una relación que tenga como eje una ética global tejida por compromisos, valores e indicadores tales como el respeto al prójimo y a la naturaleza, independiente de sus orígenes, creencias, países etc.; que haga que las personas aprendan el mundo de modo multicultural; relaciones que despiertan la sensibilidad, la capacidad de espanto frente a todas las posibilidades de aniquilamiento del ser humano y de la naturaleza; el cultivo del acto de observar el mundo, su entorno, las demás personas, para abrir las puertas del desconocido.

De esta manera, siguiendo esta lógica del deber ser, ahora cabe la pregunta: ¿Cuál será la función del profesor, interpretado como un ser reflexivo, en este proceso de innovación a través del proyecto pedagógico emancipador? 


\section{El profesor reflexivo: emancipación - innovación}

Los profesores y otras personas relacionadas a las instituciones educativas, deben desarrollar una perspectiva teórica que redefina la naturaleza de la crisis educativa y que al mismo tiempo, proporcione la base para un punto de vista alternativo sobre su formación y trabajo. En síntesis, el reconocimiento de que la actual crisis educativa tiene mucho que ver con la tendencia progresiva a la reducción del papel de los profesores en todos los niveles educativos, sería un prerrequisito teórico necesario para que los docentes se organicen con eficacia y dejen oír colectivamente su voz.

Además, según Giroux (1988, p.172), este reconocimiento deberá luchar a brazo partido no solo con la pérdida creciente de poder entre los profesores en lo que se refiere a las condiciones básicas de su trabajo, sino también contra una percepción pública sobre su papel como profesionales de la reflexión. Lo que está relacionado con la propia construcción de la identidad laboral. También está la necesidad de defender a las instituciones educativas como instituciones esenciales para el mantenimiento y el desarrollo de una democracia crítica, así como, para defender a los profesores como intelectuales transformadores que combinan la reflexión y la práctica académicas con el fin de educar a los estudiantes para que sean ciudadanos reflexivos y activos.

Para percibir la importancia de la institución como un espacio para la reflexión y para percibir los cambios que ha ido sufriendo a lo largo del tiempo, es necesario retomar la cuestión del debate, del diálogo y de los intercambios de opinión entre las esferas públicas y privadas. Para algunos pragmáticos norteamericanos como Dewey (1977) la esfera pública es el nexo entre importantes ámbitos pedagógicos en los que la democracia, como movimiento social, está ligada al esfuerzo de numerosos grupos subordinados que tratan de acoger y producir un discurso social e identificar sus implicaciones para la acción política.

Ampliando la opinión de Dewey (1977), según la cual la acción social inteligente es portadora de las mejores promesas para una sociedad más humana, los re construccionistas sociales de las décadas de 1930 y 1940 defendieron una política de individualidad social en la que los imperativos de la democracia se proponían como meta no solo en las instituciones educativas, sino en todos los ámbitos pedagógicos que reconocían la primacía de la política en la vida cotidiana. Bajo la lógica de esta postura, se escondía un énfasis en la relación entre el conocimiento y el poder; la conducta y la simulación; el compromiso y la lucha colectiva. De hecho, la esfera pública no sólo servía para producir el lenguaje de la libertad, sino que además mantenía viva la esperanza de los grupos subordinados en tanto que podrían producir, algún día, sus propios intelectuales. En las palabras de Gramsci (1997), esto significa la creación de intelectuales orgánicos, los que podrían, por una parte, llenar el vacío existente entre las instituciones académicas y los temas específicos, y, por otra, las labores de cada día. Es decir, esos intelectuales podrían 
proporcionar las habilidades morales y políticas necesarias para consolidar instituciones de educación popular y culturas y creencias alternativas.

De esta manera, queda planteado que las instituciones educativas, principalmente aquellas para la educación de los profesores, necesitan un replanteamiento como esferas públicas. Según Giroux (1988), las instituciones tal como hoy existen están peligrosamente desprovistas tanto de conciencia como de concientización social. Consiguientemente, urge desarrollar programas que posibiliten que los futuros profesores sean educados como seres reflexivos capaces de defender y practicar el discurso de la libertad y la democracia.

La educación del profesor raramente ha ocupado un espacio crítico, público o político dentro de la cultura contemporánea. No hay lugar para que el significado de lo social pueda ser recuperado y reafirmado de forma que las historias culturales de profesores y estudiantes, sus narraciones personales y voluntad colectiva puedan aglutinarse en torno al desarrollo de una esfera contra pública democrática. De hecho, es razonable pensar que los programas para la formación de los profesores están diseñados para crear intelectuales que actúen al servicio de los intereses del estado y cuya función social primaria se centra en el mantenimiento y la legitimación del status quo. Esto, según Puiggrós (1990), se puede percibir claramente en México, donde el sujeto pedagógico moderno ${ }^{3}$ puede reproducirse en un sistema educativo complejo, con un discurso escolar estructurado por un partido que por más de setenta años fue el gobernante y ocupa un gran espacio en el sistema educativo.

Al contemplar a los profesores como sujetos reflexivos y emancipadores se estaría considerando que:

a) Toda actividad humana implica alguna forma de pensamiento. Así se exalta la capacidad humana de integrar pensamiento y praxis ${ }^{4}$, resaltando la importancia del profesor como profesional reflexivo de la enseñanza;

b) Esta visión es una fuerte crítica a las ideologías tecnocráticas e instrumentales subyacentes en una teoría educativa que separa la conceptualización, la planificación y el diseño de los planes de estudio de los procesos de aplicación y ejecución; y

c) Contribuye a aclarar el papel que desempeñan los profesores en la producción y legitimación del estado.

3. Por sujeto pedagógico moderno, según Puiggrós (1990, p. 41), se entiende al mediador entre los sujetos políticos y sociales actuantes en la sociedad y el "habitus" que se pretende inculcar.

4. Aquí se entiende praxis de acuerdo al pensamiento de Agnes Heller, quien la define como acciones conscientes. A. Heller. (1982, p. 20) 
Sin embargo, al considerar a los profesores como sujetos reflexivos y emancipadores, también es importante resaltar, en términos políticos y normativos, las funciones sociales concretas que realizan los docentes. De esta manera, es necesario mirar a las instituciones educativas como lugares económicos, culturales y sociales ligados inseparablemente a los temas de poder y control (Foucault, 1991; 1995). Así las instituciones educativas no se limitarían a transmitir un conjunto de conocimientos y valores, sino que serían lugares que representan formas de conocimiento, usos lingüísticos, relaciones sociales y valores que implican selecciones y exclusiones particulares a partir de la cultura general.

Según Giroux (1988), de esta forma las instituciones educativas servirían para introducir y legitimar formas particulares de vida social. Más que instituciones objetivas alejadas de la dinámica de la política y el poder; las escuelas deben ser esferas debatidas que encarnan y expresan una cierta lucha sobre qué formas de autoridad, tipos de conocimiento, regulación moral e interpretaciones del pasado y del futuro deben ser legitimadas y transmitidas a los estudiantes. Las instituciones no son espacios neutrales y, consiguientemente, tampoco los profesores pueden adoptar una postura neutral.

En el sentido más amplio los profesores como sujetos reflexivos y emancipadores han de contemplarse en función de los intereses ideológicos y políticos que estructuran la naturaleza del discurso, las relaciones sociales de los salones de aula y los valores que ellos mismos legitiman en su enseñanza. Entonces, si los profesores han de educar a los estudiantes para ser ciudadanos activos y críticos, deberían convertirse ellos mismos en intelectuales transformadores para generar un conocimiento como emancipación y no un conocimiento como regulación.

Para ello, quizás, en términos de acciones, en sus procesos permanentes de formación, bajo el eje de la innovación, se podría llevar a cabo las siguientes experiencias:

a) El profesor para ser reflexivo necesita buscar cambios epistemológicopedagógico-político-ideológico-culturales necesarios para que eso suceda. Para ello, tendrá que, de forma permanente, investigar e incluso ser prospectivo, anticiparse a la solución de los posibles futuros problemas;

b) De la formación profesional, totalmente centrada en desempeños y ligada a tareas, se ha transitado a una formación más holística e integral que no enfoca desempeños solamente. La formación integral se orienta al desarrollo de destrezas, habilidades, capacidades de ser polivalentes, que son genéricas y clave; se asume que existen diversas maneras de lograr un desempeño experto. A través de este tipo de enfoque, la formación no se centra en la capacidad para desarrollar funciones específicas, antes bien, se orienta al desarrollo de capacidades para construir conocimientos, procesarlos, organizarlos y aplicarlos en análisis críticos y de desempeños efectivos que permitan 
transformar la cultura y los procesos sociales;

c) Dentro del marco de la docencia, de la investigación, extensión y divulgación, todo el conocimiento a ser generado, debe ser previamente cuestionado por el profesor, conjuntamente con sus alumnos, así como con su equipo de investigación, acerca del impacto que él producirá en la sociedad, en un corto y largo plazo. Según Santos (2008) acortar el tiempo, el futuro en un presente, responde a la necesidad de desarrollar proyectos que conduzcan a conocimientos que no deterioren la naturaleza y/o que no agudicen aún más las desigualdades, injusticias, violencia, enfermedades. Es necesario prever en un tiempo presente, lo que puede ocurrir con la naturaleza y con el hombre, en el futuro, es decir, las consecuencias que el conocimiento pueda producir en una sociedad;

d) La investigación tiene que ser incluyente, es decir, involucrar a profesores, alumnos, autoridades, especialistas en los respectivos temas y, principalmente, no estar orientada a una razón instrumental, sino bajo un enfoque emancipador en cuanto a la participación de los ciudadanos, a la posibilidad de la interdisciplinariedad, de los consensos y, con objetivos de colaborar hacia la mejoría de la calidad de vida de las sociedades;

e) Para esta formación constante, se necesita romper la endogamia. Transitar por otros espacios y conocer otras realidades y culturas. Realizar intercambios y experiencias en docencia, investigación y extensión con otras instituciones, países y estados (Santos, 2010); la vivencia multicultural es fundamental para la construcción de una subjetividad que sea tejida de forma crítica, por la riqueza de interpretaciones de las diversas formas de atrapar el mundo, por un equilibrio en la búsqueda de la verdad; lo que seguramente genera una práctica diferente al momento de interactuar como persona, como investigador, como profesor, como tutor. Sería romper las barreras epistemológicas que poseen como eje el imperialismo cultural y acceder a una cosmovisión multicultural;

f) Las redes interdisciplinares de trabajos y de apoyos dentro de la institución, pero sobre todo, fuera de la misma, con instituciones educativas de otros estados y países es imprescindible dentro del marco de la formación constante; de la búsqueda de soluciones para las demandas sociales; para compartir experiencias acerca de temas comunes; para consensar una ética global; para despertar la sensibilidad hacia otras posibilidades de mirar el mundo;

g) La conciencia, así como la visibilidad de la existencia de un marco compuesto por la diversidad (género, etnias, clase social, culturales, preferencia sexual, discapacidad, etc.) son elementales en el proceso de formación del profesor 
reflexivo. No puede existir un profesor reflexivo, si el sujeto desconoce la diversidad humana o no sabe convivir con la misma. Su formación debe caminar hacia las acciones de cómo tratar con cada grupo que compone la diversidad. Para ello, el profesor debe identificar su perfil, su gusto y vocación frente a los grupos que componen la diversidad humana, para prepararse y tener las habilidades pedagógicas y didácticas para tratar con los grupos;

h) El acceso a la tecnología para descubrir no solo lo que existe, sino lo que puede ser aplicado en su cotidiano en la docencia, investigación y extensión del conocimiento. Acceder y habilitarse en la tecnología son acciones obligatorias para la formación de un profesor reflexivo. Los estudiantes y profesores, las personas, de forma general, acceden al uso, por ejemplo, de la computadora. La utilización de internet nos informa, acorta distancias, proporciona relaciones virtuales, etc. Sin embargo, en términos de educación, lo más importante es que el profesor pueda conocer y, de preferencia, emplear programas y herramientas que impacten en su pedagogía y didáctica en la construcción de los conocimientos. Incluso, por ejemplo, para auxiliar a los alumnos con discapacidad en sus procesos de aprendizaje y formación, es primordial acceder a la tecnología;

i) La creatividad, la innovación y la propia reflexión solo pueden darse a partir de una realidad que inspira una objetivación. Como dice Santos (2011), incluso la solidaridad no existe antes de la crítica. Siendo así, el tiempo de ocio, así como la proximidad con el arte, son necesarios para la formación de un profesor reflexivo. La preservación de un tiempo que sea exclusivo para el ocio fortalece la capacidad de observar, sentir, percibir todo lo que compone nuestro entorno e incide en nuestra subjetivación. El acceso a los museos, a los cines, a los teatros, a las librerías, a los viajes, a los parques, a las exposiciones, a los congresos, a los talleres, a los programas de televisión, incluyéndose las comedias llas cuales nos ilustran cómo se tejen la subjetividad colectiva), son actividades que forjan la sensibilidad; conducen a pensar acerca de lo impensado; alimentan el alma para potencializar nuestras mentes a la creación constructiva; humanizan al hombre;

j) Los profesores reflexivos indiscutiblemente tienen que comprometerse y manifestarse contra las grandes injusticias, tanto dentro de las instituciones como fuera de las mismas. Ellos tienen que crear, a través de sus pensamientos y acciones, las condiciones para que sus estudiantes, mediante los conocimientos y valores desarrollados en este contexto, se vuelvan también sujetos reflexivos y transformadores. Esas son algunas reflexiones que nacen a partir de la construcción de la propia individualidad, de la subjetividad del profesor para su transformación, pues nadie puede dar lo que no tiene y, nadie puede ser lo que 
no lo es. Por tanto, la realidad es apenas un reflejo de lo que cada uno puede hacer a partir de sus voluntades;

Sin embargo, este proceso emancipador también está vinculado al contexto institucional en relación con las condiciones que se les proporciona a los profesores, para que puedan forjarse en este paradigma. Existen estudios que han sido desarrollados acerca de las condiciones laborales de los profesores universitarios; sus formaciones; las reglas y exigencias que tienen que ser cumplidas; las evaluaciones de orden cuantitativa que les son impuestas; el envejecimiento de los cuerpos académicos (Santos, 2000), entre otros temas que señalan una realidad agreste, llena de obstáculos y alejada del ambiente humanístico. Siendo así, en América Latina, se puede decir que las instituciones de educación superior presentan las siguientes consignas:

a) Salarios pocos dignos; los sueldos de los profesores están reducidos si se comparan con el poder de compra. Son innumerables los estudios sobre la pérdida gradual del salario de los profesores en relación con otras profesiones que requieren menos tiempo e inversión para la formación.

b) Cargas de trabajos agotadoras, así como el ejercicio de múltiples funciones; muchos profesores se obligan a buscar otros trabajos paralelos a su labor de docentes para complementar su sueldo. Con ello, disminuye drásticamente su calidad de vida obligándolos a una triple jornada de trabajo. La falta de tiempo, de descargas de horas laborales y los bajos salarios, les impide la búsqueda de la formación constante. Muchos profesores trabajan 60 horas semanales, ministran muchas clases, lo que los imposibilita de tener tiempo para preparar adecuadamente sus clases; tampoco tienen tiempo para realizar cursos de formación para su perfeccionamiento profesional y personal.

c) Una producción con énfasis en lo cuantitativo, en lo que se puede medir. Los procesos de evaluación a larga escala que son aplicados como forma de evaluar el desempeño educacional, consideran apenas aspectos cuantitativos del proceso de enseñanza, con énfasis exclusiva en la dimensión cognitiva; no consideran, por lo tanto, las subjetividades, las contingencias regionales, los aspectos de formación ciudadana y la dimensión afectiva del aprendizaje.

d) Un clima laboral de violencia física y psicológica. Son múltiples las patologías que surgen de esta condición de violencia física y psicológica a la que el profesor está sometido permanentemente; tales patologías producen el fenómeno del malestar docente, según Fávero (2009, p.404) “el malestar docente es fruto de un conjunto de contradicciones que ganan volumen en el escenario social en que el profesor está insertado" y que se siente impotente para reaccionar 0 solucionar.

e) La falta de reconocimiento y de credibilidad del profesor dentro de las instituciones y fuera de las mismas. El profesor se siente desprestigiado y con 
poco valor; son muchos los profesores que perdieron la alegría pedagógica de enseñar debido a la falta de reconocimiento de su trabajo, tanto por parte de los alumnos como de la sociedad que le exige el ejercicio de funciones que él no está preparado y tampoco con la formación para ello.

f) Las reformas educativas, así como las tomas de decisiones son realizadas sin la participación democrática de los profesores. Una gran parte de las reformas educativas son planeadas por especialistas o encargadas por agentes externos que desconocen el triste contexto en que se encuentran la mayoría de los educadores, de igual forma, la situación dramática de muchas instituciones educativas; sin la participación de los profesores, tales reformas se vuelven abstractas, y muchas veces, por ser impuestas, no son efectivas en las transformaciones que podrían generar.

g) El proteccionismo de los derechos de los alumnos; en contrapartida, el desvanecimiento de sus deberes. Son frecuentes las reclamaciones de los profesores que se sienten rehenes de un contexto en que perdieron su autoridad pedagógica, ellos se sienten desprotegidos por propia institución y por la sociedad que no los reconoce como protagonistas de un proceso importante de construcción de la ciudadanía.

h) El predominio de las destrezas y habilidades de orden cognitivo instrumental, y la ausencia del desarrollo de las destrezas de orden emocional. El proceso de enseñanza y de aprendizaje aún carga la racionalidad instrumental propia del modelo positivista de concebir la educación; la mayoría de los profesores no consiguen desarrollar su trabajo considerando las nuevas teorías de pensar sobre el proceso de enseñanza y de aprendizaje.

i) La presencia permanente de los profesores en sus espacios educativos, sin considerar la importancia de su movilidad para las tareas de investigación y de difusión de los conocimientos. Los profesores se consideran meros ejecutores de tareas, es decir, alguien que aplica lo que el otro planeó. Son pocos los que tienen consciencia de que su trabajo puede ser un proceso de investigación, de producción de un conocimiento didáctico, cultural y profesional.

j) La falta de apoyo financiero para las investigaciones que no sigan los rubros cuantitativos de las investigaciones aplicadas; es claramente perceptible el abismo que separa el financiamiento de los proyectos de las ciencias duras, consideradas las ciencias productivas, cuantificables, objetivas (reciben los mayores recursos). Los miserables recursos son destinados para las áreas humanas, consideradas poco productivas, que son subjetivas y que no pueden ser cuantificadas.

k) Poca accesibilidad a la tecnología como herramientas para la docencia e investigación, así como para la extensión y divulgación de los conocimientos. Además, poco acceso, debido la falta de recursos de muchos profesores que no pueden tener en su casa el acceso a internet, ni las herramientas tecnológicas. Y, cuando estas se hacen presentes en las salas de clases, son 
utilizadas equivocadamente, reproduciendo mecánicamente antiguas formas de docencia.

l) El desconocimiento de lo que sea la internacionalización de la educación, por ende, del proceso que la misma implica. A pesar de tantos avances tecnológicos, muchos profesores desconocen la dimensión planetaria de la educación en el sentido de contribuir para formar un ciudadano sensible a su planeta.

m) La vida del profesor hecha solo de tiempo laboral, sin un tiempo de ocio, y mucho menos de condiciones económicas para disfrutar o acceder a la cultura. Los profesores no disponen de tiempo o de dinero para disfrutar de una buena película, realizar un viaje, fortalecer su percepción de mundo. Muchos profesores están atrapados por su vida profesional, y no consiguen pensar en su propia historia de vida. Según Fávero y Tonieto (2010, p.25) “la historia de vida es considerada un abordaje investigativo que se engendra de modo significativo en los procesos de formación de las identidades profesionales".

Todo ello retrata algunos de los puntos que obstaculizan de manera determinante la construcción del profesor como sujeto reflexivo. Giroux (1988) al igual que Freire (1974), piensa que uno de los componentes centrales de la categoría de los profesores reflexivos y emancipadores es la necesidad de conseguir que lo pedagógico sea más político y lo político más pedagógico. Hacer lo pedagógico más político significa insertar la instrucción escolar directamente dentro de la esfera política al demostrar que dicha instrucción representa una lucha para determinar el significado y, al mismo tiempo, una lucha en torno a las relaciones de poder. Dentro de esta perspectiva, la reflexión y la acción críticas se convierten en parte de un proyecto social fundamental para ayudar a los profesores y a los estudiantes a desarrollar una fe duradera en la lucha contra las injusticias económicas, políticas y sociales, así como para humanizarse más como parte de esa lucha.

Hacer lo político más pedagógico significa servirse de la pedagogía para encarnar intereses políticos de naturaleza liberadora. Es servirse de formas pedagógicas que posibiliten la formación del profesor, así como la de los estudiantes en seres críticos; es hacer problemático el conocimiento; recurrir al diálogo crítico y afirmativo y llegar a consensos. Por lo tanto, el punto de partida pedagógico para este tipo de intelectuales no es el profesor y el estudiante aislados, sino los individuos en grupos dentro de sus múltiples contextos culturales, sociales, raciales, históricos, sexuales, que miren conjuntamente con la particularidad de sus intereses, problemas, sueños, aspiraciones y desencantos. Como dice Agnes Heller (1982), una relación libertadora es aquella en la que el otro deja de ser objeto y pasa a ser objetivo. En esta perspectiva, se podría creer en la innovación en las instituciones educativas: cuando se genere un ethos institucional que posibilite la formación del profesor reflexivo emancipador; en que el propio conocimiento pasa a ser cuestionado $y$, cuando se analizan sus medios y fines; cuando las condiciones de orden económico, social, ideológica, política, cultural incentiven 
la generación de conocimientos que conduzcan a una transformación individual y, posteriormente colectiva de la sociedad.

\section{Reflexiones Finales}

La educación continúa es el medio para que el hombre encuentre los límites para la razón; la fuerza de la reflexión y la autodeterminación; la posibilidad de descosificar su conciencia; del reencontrar al hombre humano en el hombre tecnológico; de transformar hombres fríos en amables; de cambiar la sinrazón por la razón y la ausencia de sentido por el sentido.

Es el hombre quien hace su propia historia. El hombre no se humaniza para cumplir los dictámenes de la naturaleza. De acuerdo a este pensamiento, se podría postular que la revolución para la transformación pedagógica y para la transformación del ser, primeramente, pasa por la subjetividad, por la participación en un proceso lento y celular, por una revolución invisible en la cual estudiantes y profesores transitan de la particularidad hacia la individualidad y hacia el propio proceso emancipador. Y es en este momento cuando el hombre toma conciencia de su alienación, de su realidad, de sus sentimientos, de su dureza, de su capacidad destructora, de su explotación y de su condición humana.

Si pudiéramos hablar del tiempo y de la historia concebida como marcha, tendríamos, según Octavio Paz (1996) que el tiempo cristiano sería finito: comenzaba en la Caída y terminaba en la Eternidad, al otro día del Juicio Final. En el mismo sentido, podemos decir que el tiempo moderno, revolucionario o reformista, rectilíneo o en espiral, es infinito. Y el revolucionario es aquel que interminablemente, accede a la historia y al futuro como un sujeto social, transformador y emancipador.

Sin embargo, quedan aún muchos desafíos para que ello se vuelva realidad: cómo promover y crear condiciones para que el profesor tenga una formación que le permita dar el "giro" sobre sí mismo y se transforme de "ser particular hacia ser individual"; para que en su práctica se vuelva líder de proyectos interconectados con lo cotidiano y permeados por una epistemología que no sea técnica, que se emancipadora y multicultural; para construir un proyecto social donde lo pedagógico se haga más político y lo político más pedagógico; para que las instituciones educativas, así como los profesores rescaten su credibilidad; para que el profesor consiga crear su identidad; para que profesor y estudiantes ejerzan sus ciudadanías; para que el profesor no se deje alienar por las racionalidades reguladoras de la “modernización”. Finalmente ¿Cómo conciliar la lucha entre su propia existencia y su formación? 


\section{Bibliografía}

DEWEY, Jonh. The Relations of Theory and Practice. Southern Illinois: University Press, 1977.

FÁVERO, Altair Alberto. Políticas de formação Pedagógica: possibilidades de superar o mal-estar docente. In: Angelo Vitório Cenci; Claudio Almir Dalbosco; Eldon H. Mühl. (Org.). Sobre Filosofia e Educação: racionalidade, diversidade e formação pedagógica. 1 ed. Passo Fundo: UPF, 2009, v. 1, p. 403-419.

.; TONIETO, Carina. Educar o educador: reflexões sobre formação docente.

Campinas/SP: Mercado de Letras, 2010.

FOUCAULT, Michel. El Discurso del poder. México: Folios, 1983.

. Microfísica del poder. Madrid: La Piqueta, 1991.

Tecnologías del Yo. Barcelona: Paidós, 1995.

Hermenéutica del sujeto. Madrid: Akal, 2005.

FREIRE, Paulo. Pedagogía del Oprimido .México: Siglo XXI, 1974.

GIROUX, Henry. Los Profesores como intelectuales hacia una pedagogía crítica del aprendizaje. Barcelona: Ediciones Paidós, 1988.

GRAMSCI, Antonio. Los intelectuales y la organización de la cultura. México: Juan Pablos Editor, 1997.

HELLER, Agnes. Para Mudar a Vida. São Paulo: Editora Brasiliense, 1982.

LAMPERT, Ernani. La Universidad en el siglo XXI: perspectivas y desafíos. In: Revista Galego-Portuguesa de Psicología y Educación, v.2, nº 2. La Coruña, 1998.

LUCARELLI, Elisa. Innovaciones en el Contexto de la Relación Universidad - Sociedad. In: Universidade e Integração no Cone Sul Série Universidade. Brasil: Editora da Universidade, 1992. p. 127-135

PAZ, Octavio. Ideas y Costumbres II, Obras Completas, tomo 10. México: FCE, 1996. PUIGGRÓS, Adriana. Imaginación y crisis en la educación latinoamericana. México: Alianza Editorial, 1990.

SANTOS López, Aristeo. Académicos de la Universidad Autónoma del Estado de México: inversión y recuperación de los recursos humanos. México, Toluca: UAEMéx, 2000.

. Erudito Global FEA/USP: experiencia de aplicación a la internacionalización de la educación. México, Toluca: UAEMéx, 2010.

SANTOS, de Sousa Boaventura. 0 social e o político na transição pós-moderna. In: Revista de cultura e política, vol.31. São Paulo: Editora Cedec, 1993, p. 181-207

. Pela mão de Alice. O Social e o político na Pós- Modernidade. Lisboa:

Editora Afrontamento, 1994.

. Um discurso sobre as ciências. Lisboa: Editora Afrontamento, 1995.

. Para uma pedagogia do conflito. In: SILVA, Luiz Heron et al. Novos mapas culturais, novas perspectivas educacionais. Porto Alegre: Editora Sulina, 1996.

A gramática do tempo. São Paulo: Editora Cortez, 2008.

. 0 espelho no mundo. In: Jornaldeletras.pt, sessão Ideias. 12 a 25 de janeiro de 2011. Brasil, Rio Grande do Sul, Passo Fundo, 2011. p. 26-31. 
Recebido em junho de 2012

Aprovado em setembro de 2012

Altair Alberto Fávero é pós-doutor (Bolsista Capes) pela Universidad Autónoma del Estado de México (UAEMéx), doutor em educação pela Universidade Federal do Rio Grande do Sul e professor e pesquisador no curso de Filosofia, e na pósgraduação em educação da Universidade de Passo Fundo. Email: altairfaverola gmail.com

Marisa Fátima Roman é mestre e doutora em Educação pela Universidade Autônoma do Estado do México (UAEMéx). Email: arisy2kamsn.com

Aristeo Santos López é doutor em educação pela Universidade Estadual de Campinas, pós-doutor em Administração pela Universidade de São Paulo e professor da Universidade Autônoma do Estado do México. Email: arisan3agmail. com 